\title{
P02.06. The effect of massage therapy for breast surgery patients
}

\author{
N Drackley ${ }^{*}, \mathrm{~B}$ Bauer \\ From International Research Congress on Integrative Medicine and Health 2012 \\ Portland, Oregon, USA. 15-18 May 2012
}

\section{Purpose}

Massage therapy is used as an adjunct to conventional medical therapy. The goal of this pilot was to evaluate the effect of massage therapy on pain, anxiety, tension and overall wellbeing after breast surgery. The secondary goal was to evaluate the feasibility of a fee-for-service delivery model in a hospital setting.

\section{Methods}

A 3-month pilot was performed offering massage therapy to postoperative breast surgical patients. A certified massage therapist approached patients the day after surgery. Massage duration was determined by discussion between the therapist and patient. Massage was offered at a fee of $\$ 1 /$ minute and billed through the institutional billing system. Pain, anxiety and tension levels were documented pre and post massage. Patients completed an anonymous survey regarding their experience.

\section{Results}

Of 64 patients seen during the pilot, 46 patients (72\%) elected to have massage. Eighteen patients declined due to: cost $(n=2)$, too ill $(n=3)$, not interested $(n=11)$, dismissed $(n=2)$. The mean duration of therapy was 23 minutes (range $8-45$ ). Patients reported massage as very effective for: stress relief (76\%), relaxation (82\%), pain relief (64\%), and somewhat effective for: stress relief (21\%), relaxation (18\%) and pain relief (31\%). In terms of general feelings of wellness, $83 \%$ of patients reported massage as very effective. Patient comments regarding the experience were positive. Seventy- nine percent of patients returned post massage surveys and $100 \%$ were satisfied (91\% very satisfied and 9\% satisfied) and 100\% would recommend postoperative massage to other surgical patients.

Mayo Clinic, Rochester, USA and take full advantage of:
- Convenient online submission

- Thorough peer review

- No space constraints or color figure charges

- Immediate publication on acceptance

- Research which is freely available for redistribution
- Inclusion in PubMed, CAS, Scopus and Google Scholar therapy for breast surgery patients. BMC Complementary and Alternative Medicine 2012 12(Suppl 1):P62.
Cite this article as: Drackley and Bauer: P02.06. The effect of massage 